\title{
Surface Charge Regulation of MIL-100(Fe) by Anion-Exchange for Demulsifying the Cationic Surfactant-Stabilized O/W emulsion
}

Rui Wang, ${ }^{a, b}$ Miao Fu, ${ }^{b}$ Juncai Yang, ${ }^{b}$ Yunqian Zhong, ${ }^{b}$ Ruiyang Zhang, ${ }^{b}$ Qian Zhang, ${ }^{b}$ Yucheng Liu, ${ }^{c}$ Ying Zhou ${ }^{a, b, *}$

a State Key Laboratory of Oil and Gas Reservoir Geology and Exploitation, Southwest Petroleum University, Chengdu, Sichuan Province, 610500, China

${ }^{\mathrm{b}}$ Carbon Neutralization Research Institute, School of New Energy and Materials, Southwest Petroleum University, Chengdu, Sichuan Province, 610500, China

c College of Chemistry and Chemical Engineering, Southwest Petroleum University, Chengdu 610500, Sichuan Province, China

* Corresponding author

E-mail: yzhou@swpu.edu.cn; Fax: +86 28 83037406; Tel: +86 2883037401 


\section{CONTENT}

Simulation method.

Figure S1 The photographs of original emulsion and diluted emulsion at 0 day (a), 1 day (b), 3 days (c) and 7 days (d) . .52

Figure S2 Optical and TEM images of samples (b is MIL-100(Fe), c is $\mathrm{H}_{2} \mathrm{PO}_{4}^{-}-\mathrm{MIL}-100(\mathrm{Fe})$, d is $\left.\mathrm{HPO}_{4}{ }^{2-}-\mathrm{MIL}-100(\mathrm{Fe})\right)$ . .53

Figure S3 FT-IR spectra of samples ..S4

Figure S4 Optical microscope images of $\mathrm{O} / \mathrm{W}$ model emulsion (a), statistics of size for the emulsion droplets (b) . .55

Figure S5 Optical microscope images of $\mathrm{O} / \mathrm{W}$ model emulsion before (a) and after demulsification by MIL-100(Fe) (b), $\mathrm{H}_{2} \mathrm{PO}_{4}{ }^{-}-\mathrm{MIL}-100(\mathrm{Fe})$ (c) and $\mathrm{HPO}_{4}{ }^{2-}-\mathrm{MIL}-100(\mathrm{Fe})$ (d) ....S6

Figure S6 The demulsification efficiency of phosphate-exchanged MIL-100(Fe) at different dosages. . .57

Figure S7 The influence of $\mathrm{pH}$ on the stability of emulsion ..S8

Figure S8 The demulsification efficiency of phosphate-exchanged MIL-100(Fe) at different salinities ..S9

Figure S9 The XPS spectra of the phosphate-exchanged MIL-100(Fe) before and after demulsification .$S 10$

Figure S10 The standard curve of the concentration of CTAB by HPLC. S11

Figure S11 Images of two oleic acid drops before (a) and after (b) molecular dynamic simulation .$S 12$

Figure S12 Images of two oleic acid drops with an existence of MIL-100(Fe) before (a) and after (b) molecular dynamic simulation. .$S 13$ 


\section{Simulation method}

To understand the fusion of emulsion drops under a mediation of MIL-100(Fe), we conducted the molecular dynamics (MD) simulation. The MIL-100(Fe) model was constructed according to the previous reports, ${ }^{1,2}$ optimized and simulated using the Forcite module of Materials Studio 8.0. Detail method was described as following:

MD simulation was executed following the geometric optimization. The forcefield type, summary methods of electrostatic interaction and van der Waals forces for all theoretical calculations were universal forcefield, Ewald and atom based, respectively. MD simulation ran with the NVT ensemble at $298.0 \mathrm{~K}$. And the methods of random and nose were employed as initial velocities and thermostat. 


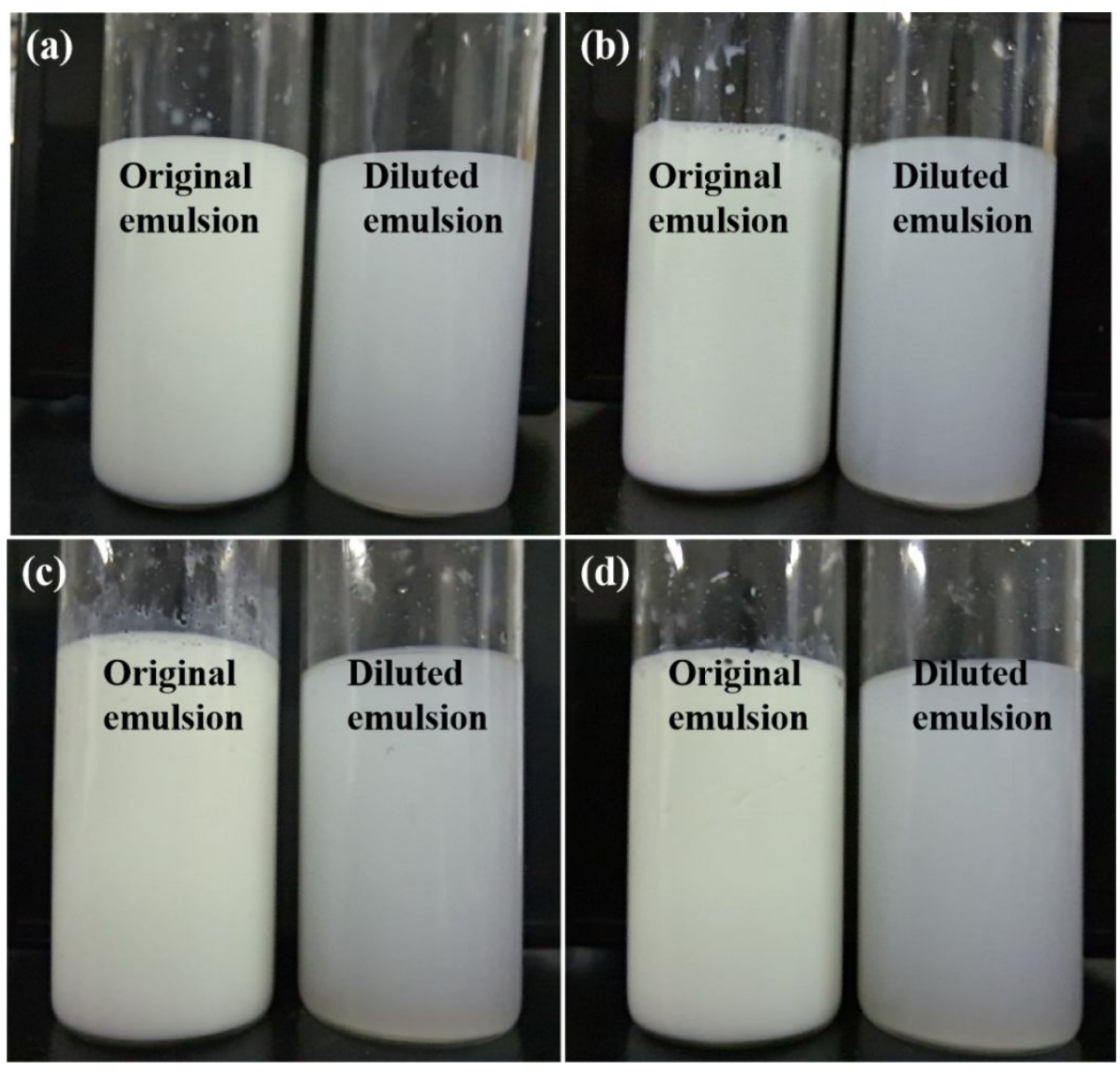

Figure S1 The photographs of original emulsion and diluted emulsion at 0 day (a), 1 day (b), 3 days (c) and 7 days (d) 


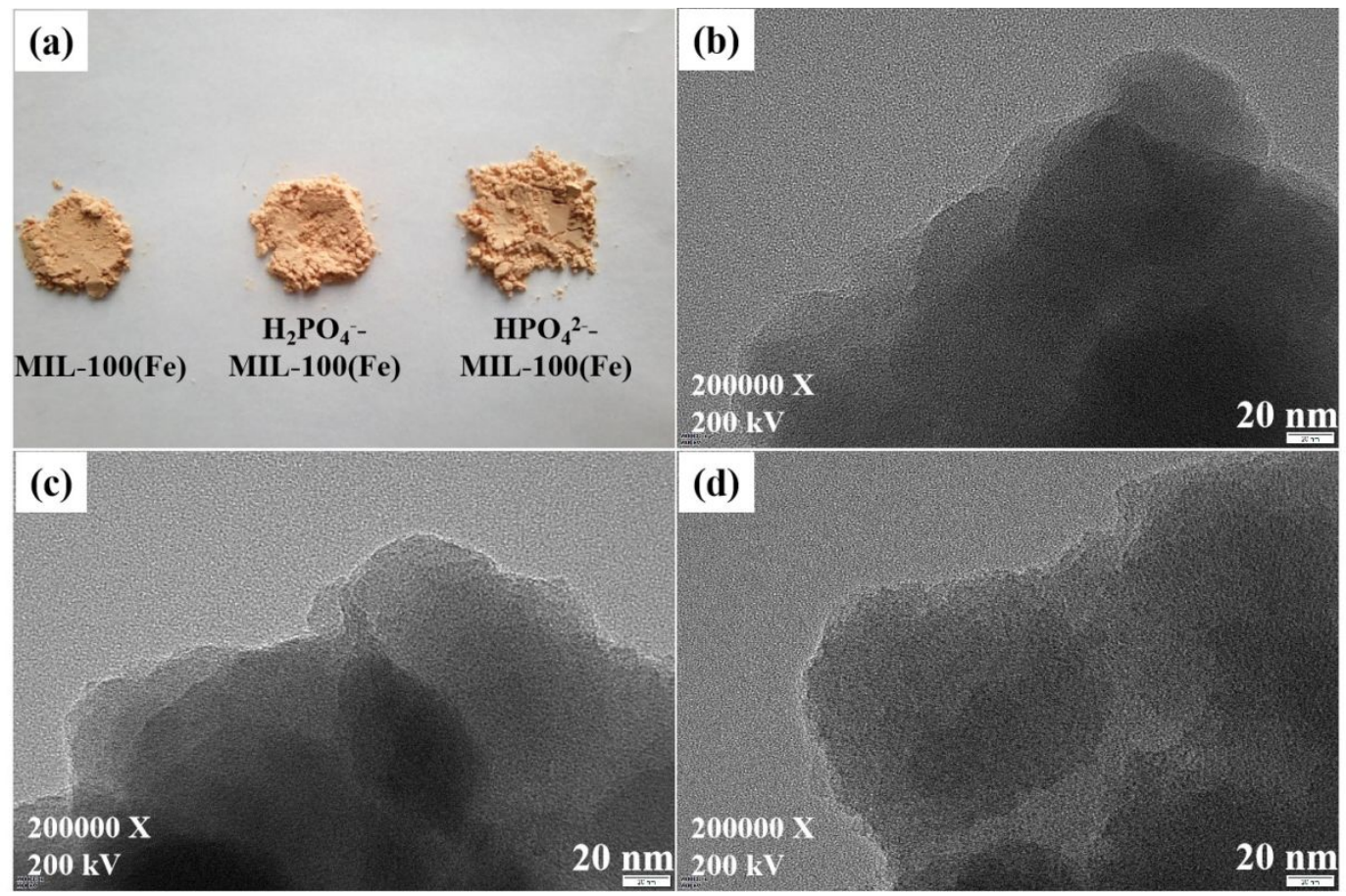

Figure S2 Optical and TEM images of samples (b is MIL-100(Fe), c is $\mathrm{H}_{2} \mathrm{PO}_{4}^{-}-\mathrm{MIL}-100(\mathrm{Fe})$, $\mathrm{d}$ is $\left.\mathrm{HPO}_{4}{ }^{2-}-\mathrm{MIL}-100(\mathrm{Fe})\right)$ 


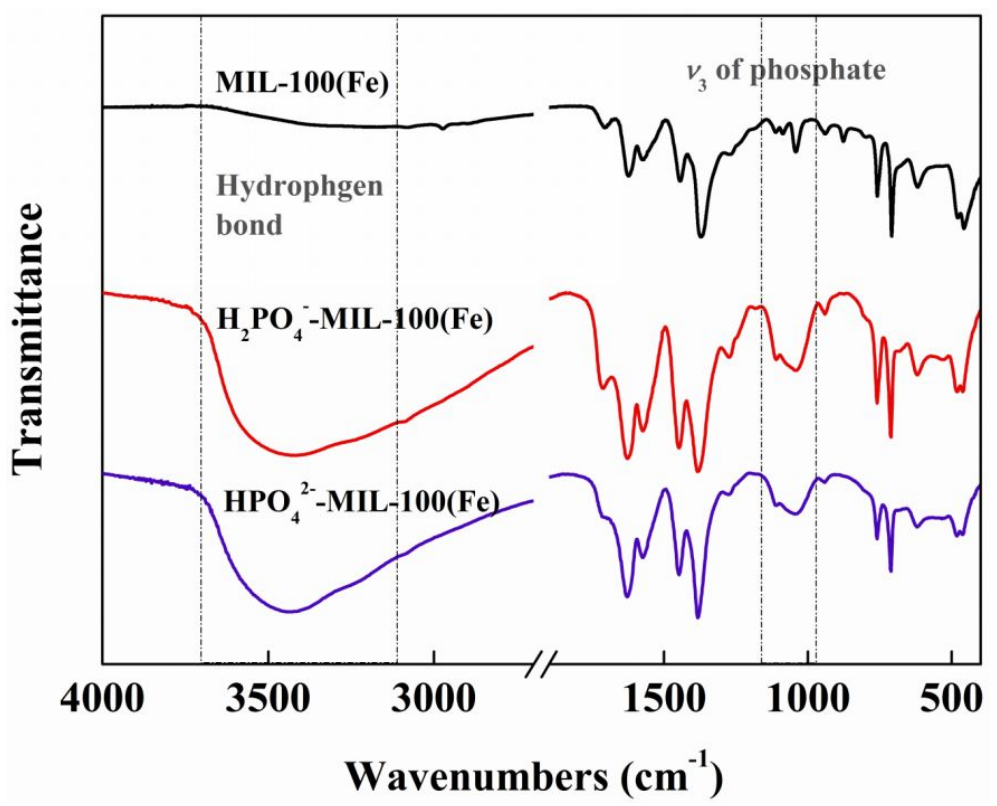

Figure S3 FT-IR spectra of samples 

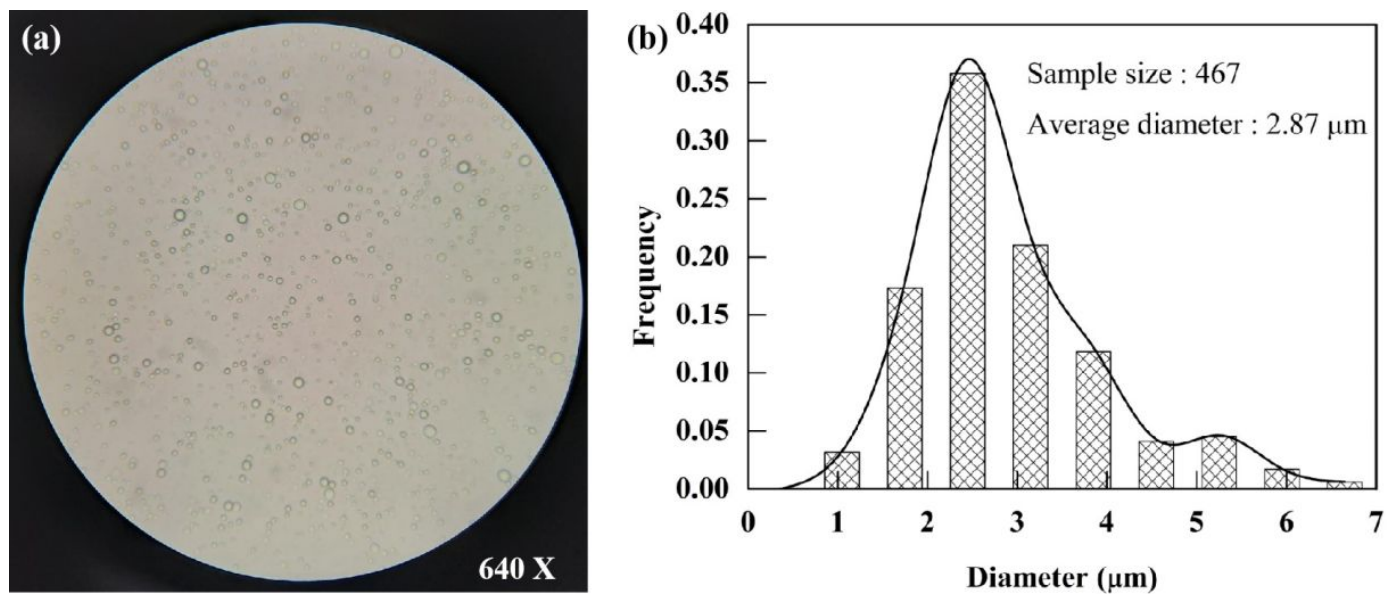

Figure S4 Optical microscope images of $\mathrm{O} / \mathrm{W}$ model emulsion (a), statistics of size for the emulsion droplets (b) 


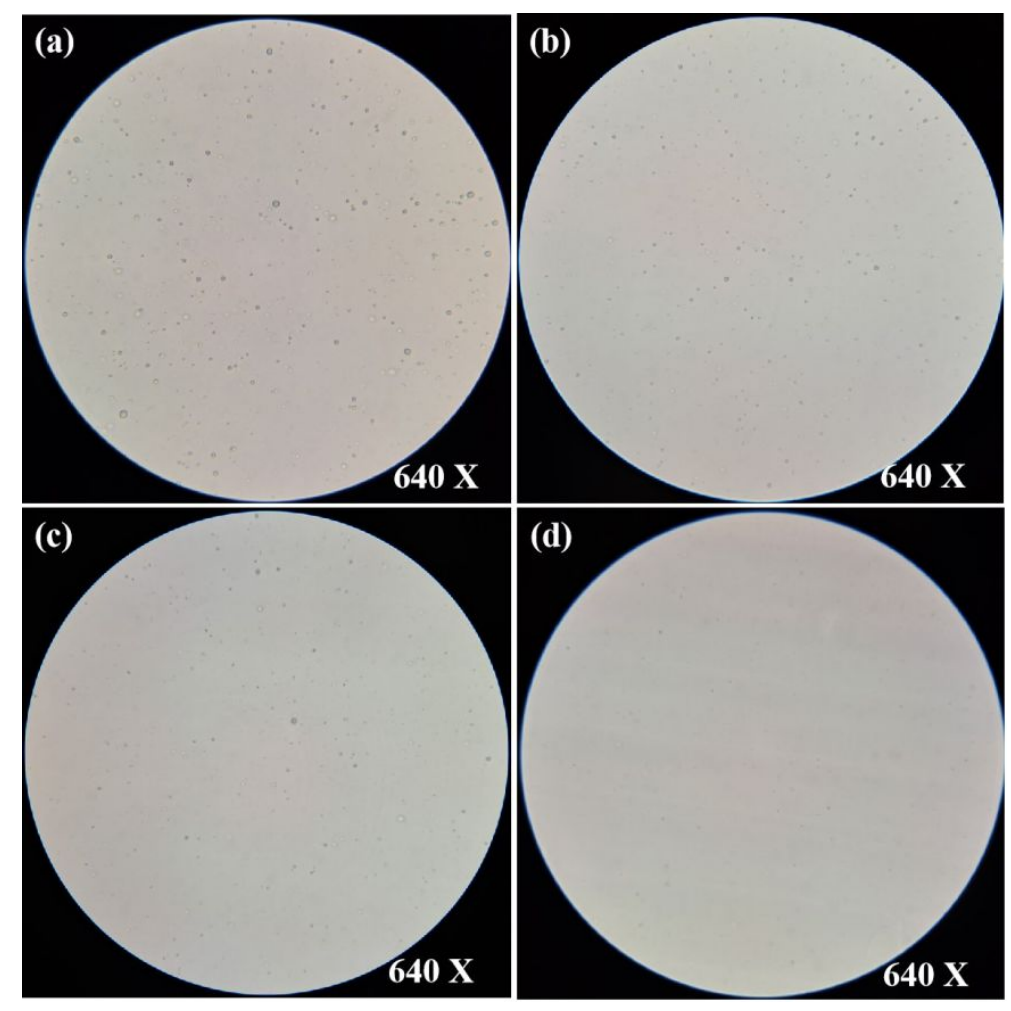

Figure S5 Optical microscope images of $\mathrm{O} / \mathrm{W}$ model emulsion before (a) and after demulsification by MIL-100(Fe) (b), $\mathrm{H}_{2} \mathrm{PO}_{4}^{-}-\mathrm{MIL}-100(\mathrm{Fe})(\mathrm{c})$ and $\mathrm{HPO}_{4}{ }^{2-}-\mathrm{MIL}-100(\mathrm{Fe})(\mathrm{d})$ 


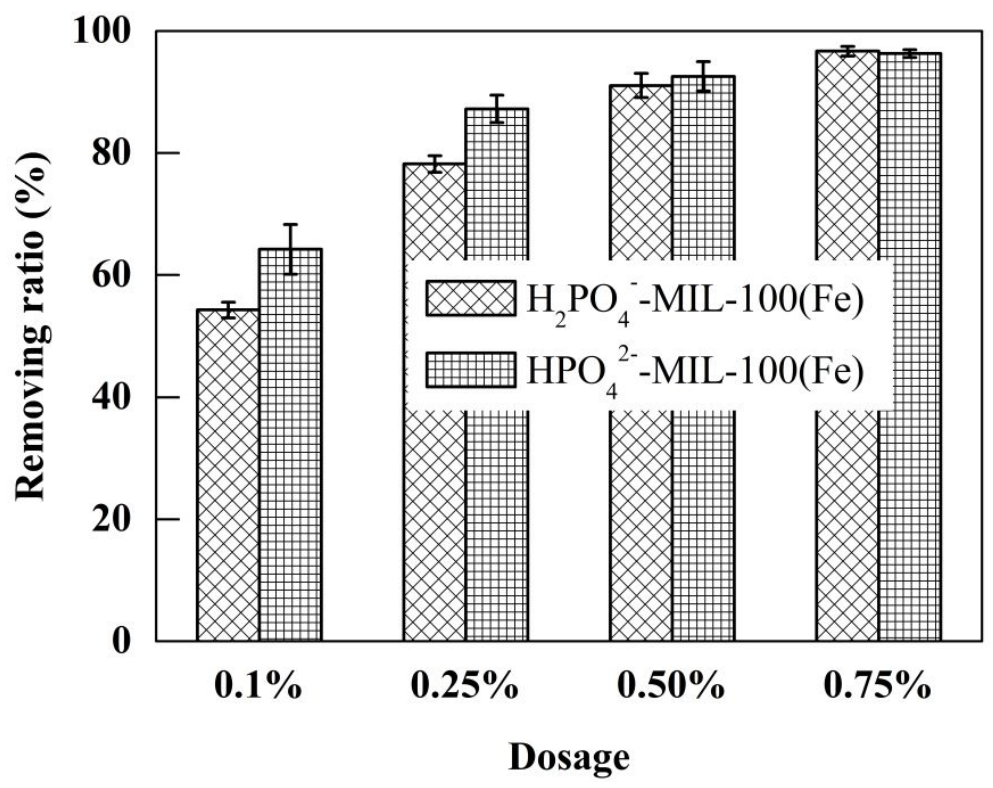

Figure S6 The demulsification efficiency of phosphate-exchanged MIL-100(Fe) at different dosages 


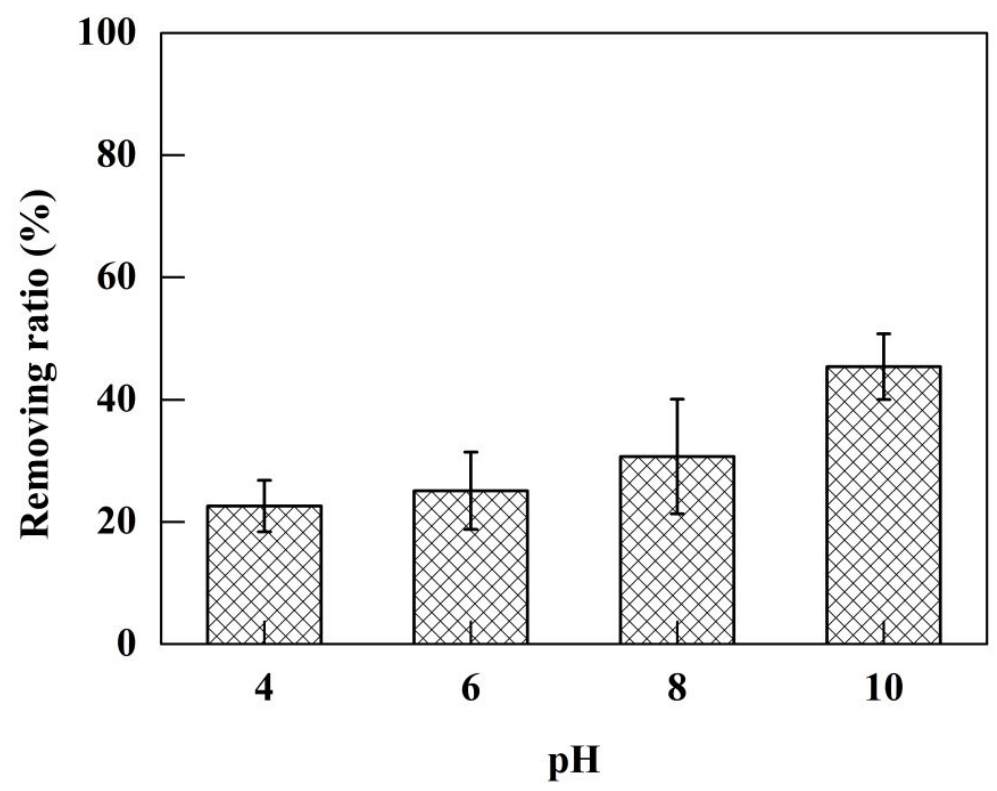

Figure S7 The influence of $\mathrm{pH}$ on the stability of emulsion 


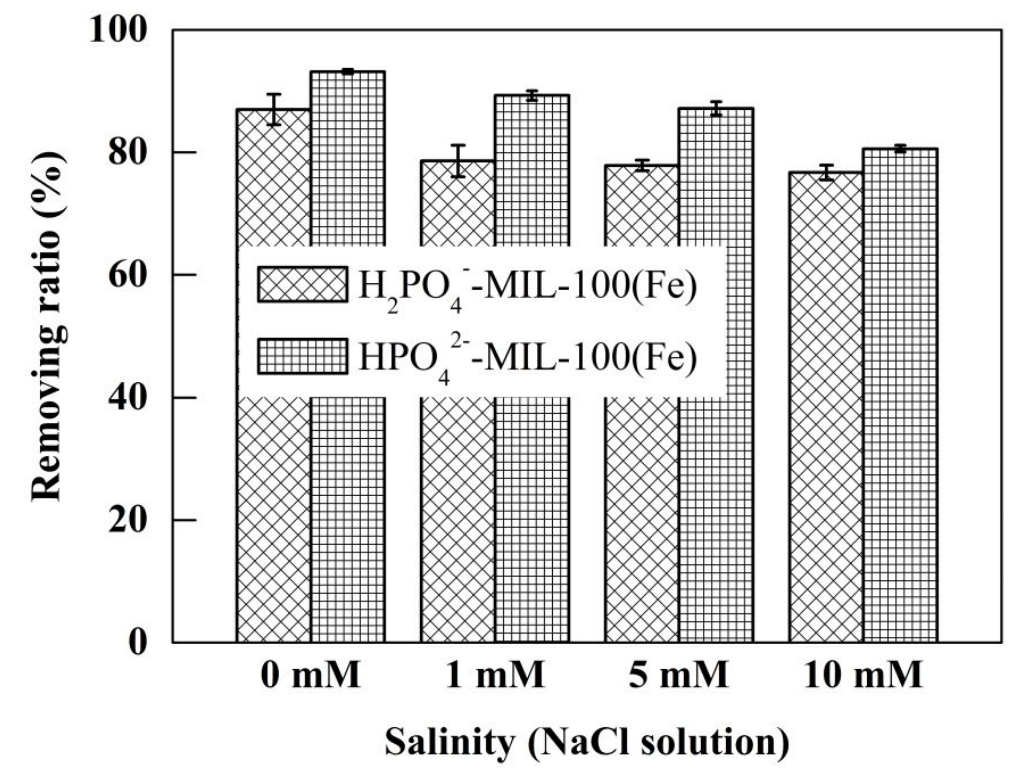

Figure S8 The demulsification efficiency of phosphate-exchanged MIL-100(Fe) at different salinities 


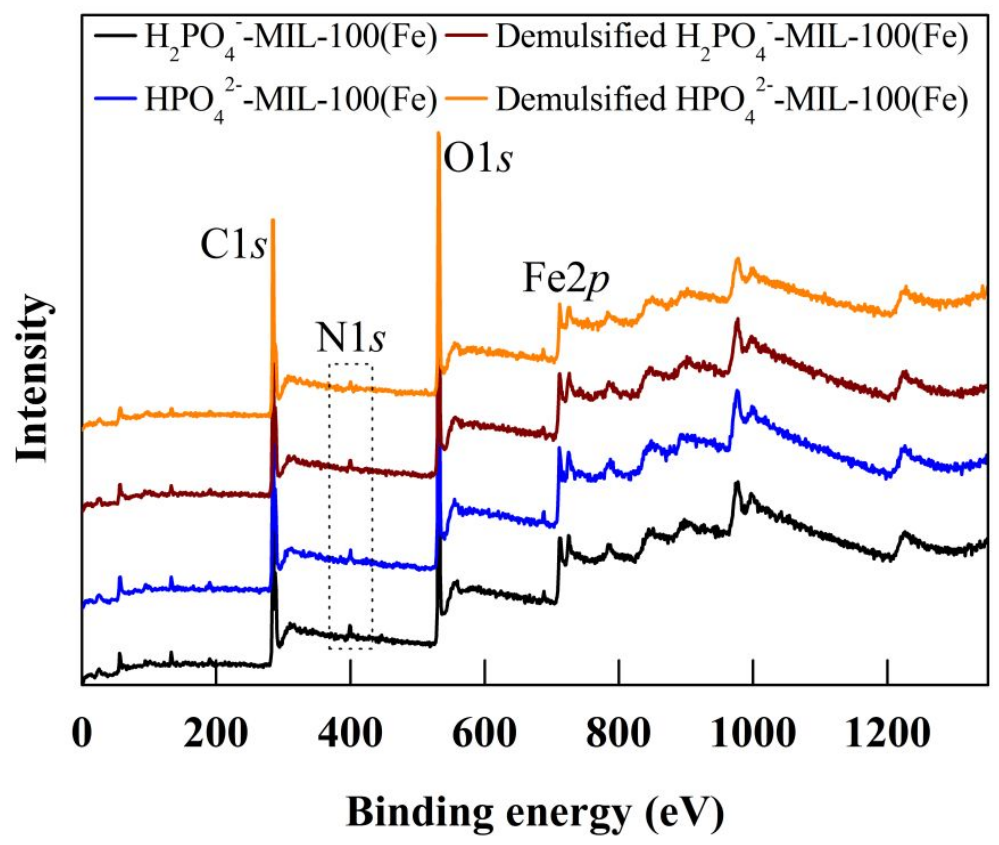

Figure S9 The XPS spectra of the phosphate-exchanged MIL-100(Fe) before and after demulsification 


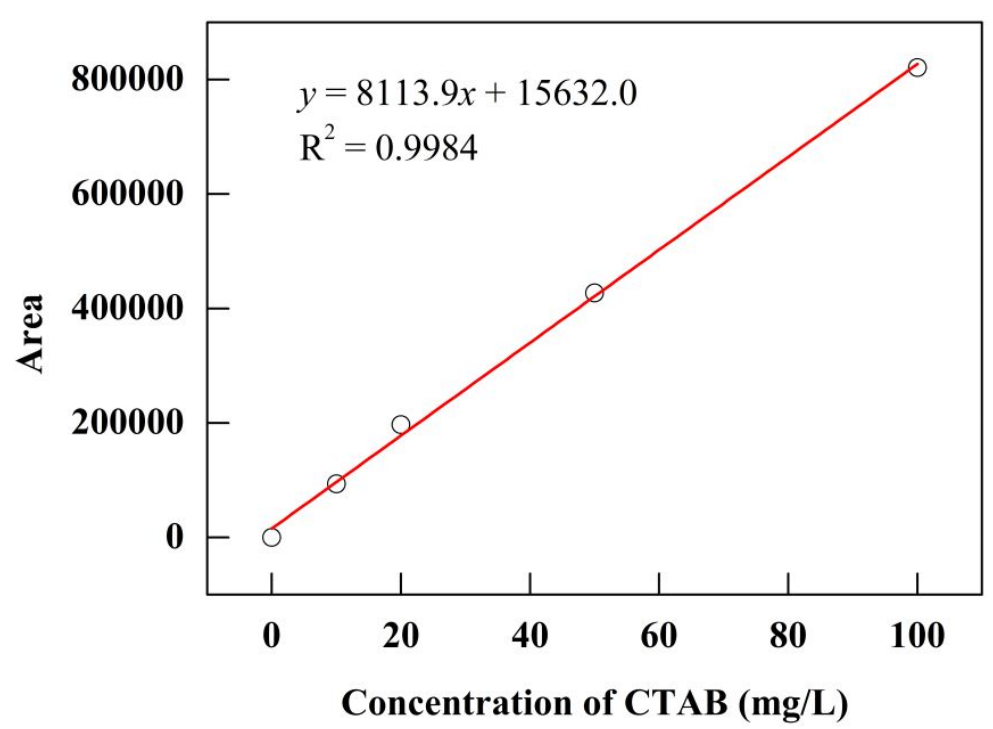

Figure S10 The standard curve of the concentration of CTAB by HPLC 


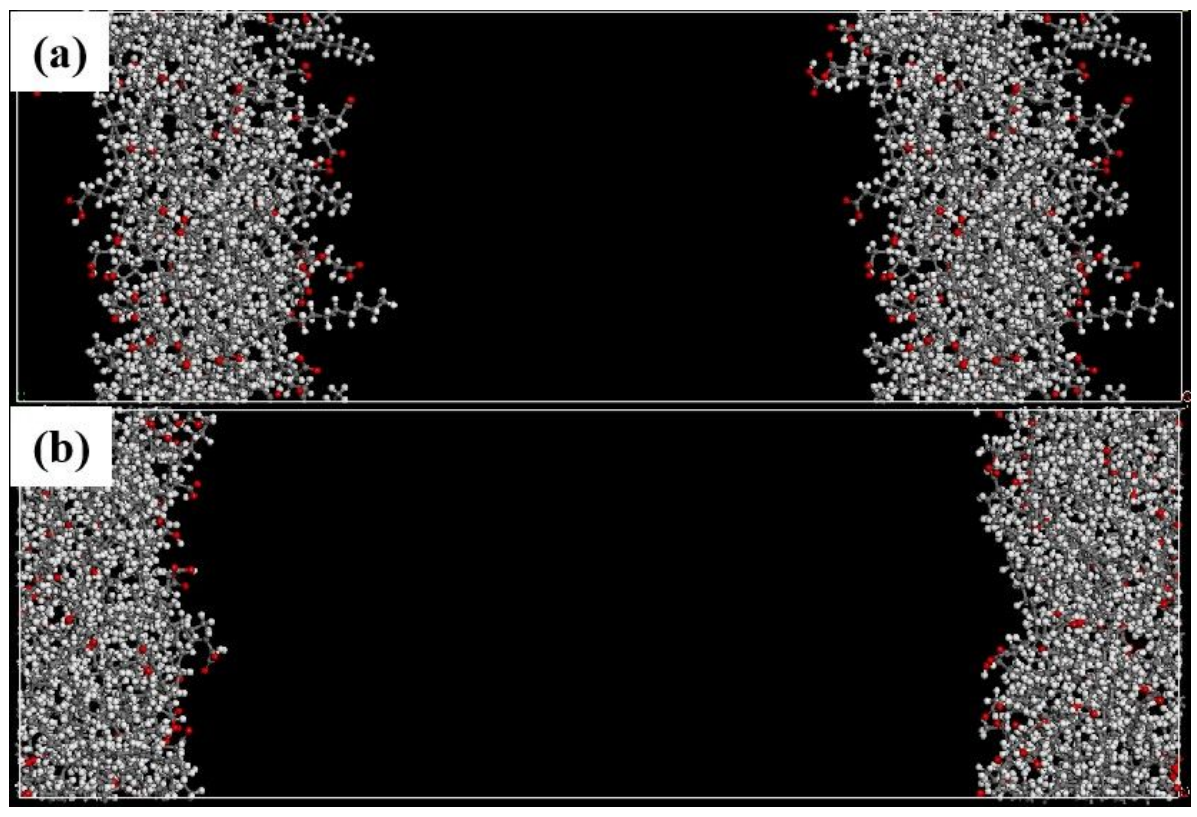

Figure S11 Images of two oleic acid drops before (a) and after (b) molecular dynamic simulation 


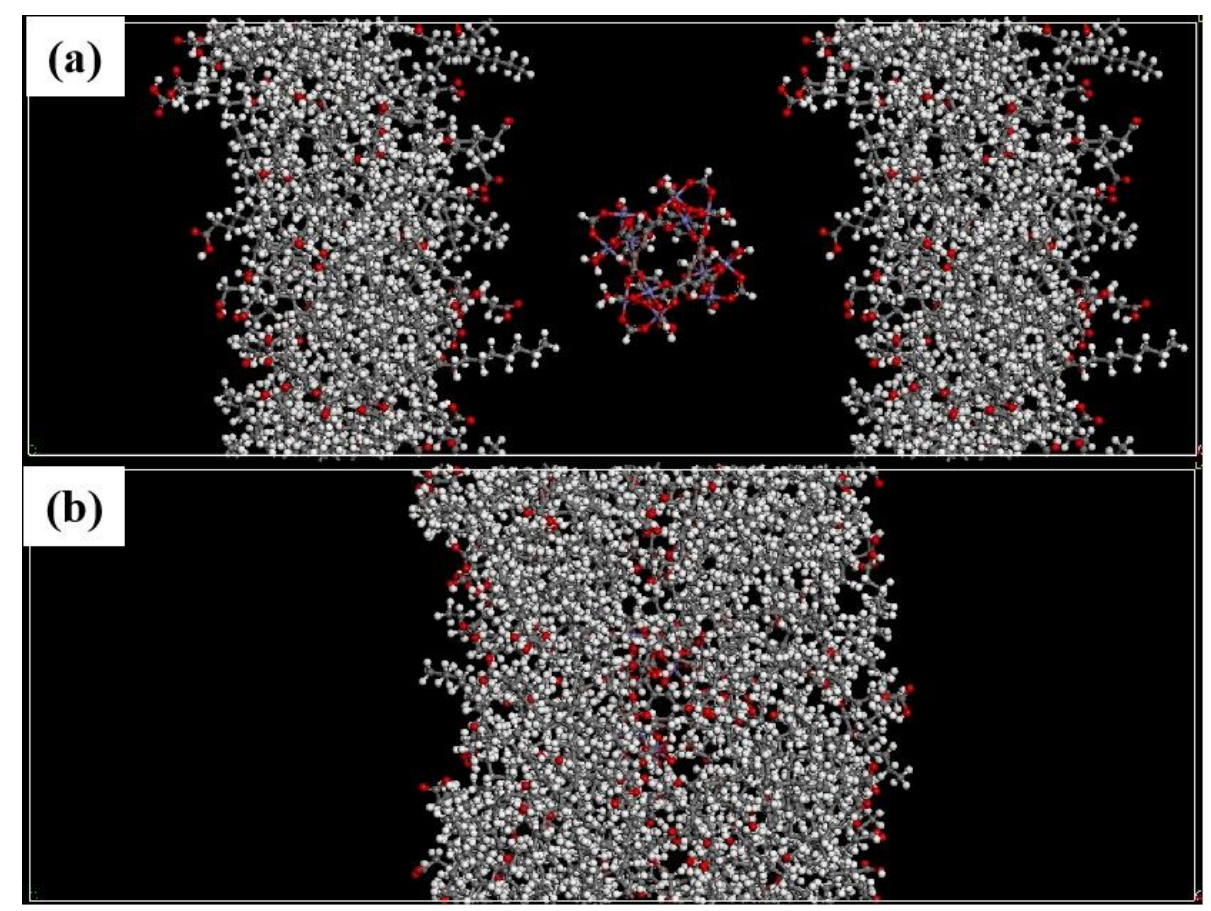

Figure S12 Images of two oleic acid drops with an existence of MIL-100(Fe) before (a) and after

(b)

molecular

dynamic

simulation 


\section{References}

[1] Chen, Y. R.; Liou, K. H.; Kang, D. Y.; Chen, J. J.; Lin, L. C. Investigation of the Water Adsorption Properties and Structural Stability of MIL-100(Fe) with Different anions. Langmuir, 2018, 34, 4180-4187.

[2] Wang, H.; Rassu, P.; Wang, X.; Li, H. W.; Wang, X. R.; Wang, X. Q.; Feng, X.; Yin, A. X.; Li, P. F.; Jin, X.; Chen, S. L.; Ma, X. J.; Wang, B. An Iron-Containing Mrtal-Organic Framework as a Highly Efficient Catalyst for Ozone Decomposition. Angew. Chem. Int. Edit., 2018, 57, 16416-16420. 